\title{
Intraspinal Transplantation of Fetal Raphe Neurons and Competition With Sprouting Host Spinal Afferents
}

\author{
Vicky R. Holets \\ The Miami Project and Departments of Neurological Surgery and Cell Biology \& Anatomy, University of
Miami School of Medicine, 1600 NW 10th Ave. (R-48), Miami, FL 33136, USA
}

Liu and Chambers $/ 3 /$ were the first to demonstrate collateral sprouting in the spinal cord, followed by other examples of lesioninduced sprouting in the dorsal columns $/ 2 /$. The signals for sprouting in the CNS are not known, and the functional consequences of sprouting have not been addressed in most systems. Sunde and Zimmer /5/ pointed out that sprouting is not equivalent to regeneration. The lesioned fibers do not grow back to their original targets, but other fibers invade and take over the terminal areas of the lesioned fibers. These authors suggested that the sprouting nerve fibers may in fact block the regenerative growth of the original fibers by filling vacated synaptic sites.

Recent intraspinal transplantation studies using fetal brainstem neurons containing 5hydroxytryptamine (5-HT) from the raphe nuclei demonstrate that extensive reinnervation of the lesioned spinal cord is possible, and partial amelioration of functional deficits has been observed /1,4/. In these studies, the raphe cells were transplanted into the lesioned spinal cord either at the time of lesion or within one week post-lesion.

The present study describes the competition and interaction between sprouting primary afferent fibers and descending catecholaminergic fibers with the outgrowth from an intraspinal transplant of fetal raphe neurons transplanted either 7 days or 3 months post-lesion.

Adult Sprague-Dawley rats received an intrathecal injection of 5,7-dihydroxytryptamine (5,7-DHT) at the C6 spinal cord level to lesion the descending serotonergic system. At 7 days or 3 months post-lesion, cell suspensions of E14.515 fetal raphe cells were transplanted at the T8 spinal cord level. The control groups included unoperated controls, sham 5,7-DHT lesioned animals, and 5,7-DHT lesioned animals that received sham transplants at either 7 days or 3 months post-lesion.

The immunohistochemical localization of serotonin (5-HT), calcitonin gene-related peptide (CGRP), dopamine $\beta$-hydroxylase (D $\beta \mathrm{H})$ and phenylethanolamine $\mathrm{N}$-methyltransferase (PNMT) was performed at 1, 3, 6, 12 and 18 months post-transplant. A Zeiss IBAS-2000 image analysis system was used to quantify the percent area of the IML that was covered by 5HT, CGRP-, D $\beta H$, and PNMT-immunofluorescent fibers. The total cross sectional areas of the spinal cords taken from all the groups indicated that there was no change in the total area of the spinal cord or of the IML region following the 5,7-DHT lesion and the transplant.

Animals with 5,7-DHT lesions showed extensive sprouting of CGRP-, D $\beta \mathrm{H}$ - and PNMTimmunoreactive fibers in the intermediolateral cell column (IML) at 1 month post-lesion that stabilized by 3 months post-lesion and did not change up to 18 months post-lesion. Animals receiving transplants 7 days after a 5,7-DHT lesion exhibited extensive innervation of IML and other areas of the spinal cord by 5-HTimmunoreactive fibers in the T6-T8 spinal levels, and did not show sprouting of the CGRP-, D $\beta$ or PNMT-containing fibers. In contrast, animals receiving raphe transplants at 30 days postlesion showed only sparse reinnervation of IML by the 5-HT cells, and sprouting of the CGRP-, $\mathrm{D} \beta \mathrm{H}$ and PNMT-immunoreactive fibers was observed.

The results of the present study demonstrate that compensatory sprouting of CGRP-, D $\beta \mathrm{H}$, and PNMT-immunoreactive fibers occurs in the IML in the thoracic spinal cord following a specific lesion of the descending serotonergic path- 
way. This sprouting can be blocked by transplantation of fetal raphe neurons at 7 days postlesion, but not when the transplant was done at 3 months post-lesion. These results are consistent with the idea that there is a hierarchy of sprouting between lesioned and unlesioned nerve fibers, and that this sprouting may block the ingrowth of transplanted, or regenerating nerve fibers.

\section{ACKNOWLEDGEMENTS}

This work was supported by The Miami Project to Cure Paralysis, The Daniel Heumann Fund for Spinal Cord Research, and the American Heart Association, Florida Affiliate.

\section{REFERENCES}

1. Foster GA, Brodin E, Gage FH, Maxwell DJ, Roberts MHT, Sharp T. In: Dunnett SB, Richards SJ, eds, Prog. Brain Res 1990; 82: 247-259.

2. Goldberger ME, Murray M. J Comp Neurol 1974; 158: 37-54.

3. Liu CN, Chambers WW. Arch Neurol Psychiat 1958; 79: 46-61.

4. Privat A, Mansour H, Geffard M. In: Gash DM, Sladek JR Jr, eds, Prog Brain Res 1988; 78: 155-166.

5. Sunde N, Zimmer J. Acta Neurol Scand 1981; 63: 323335. 

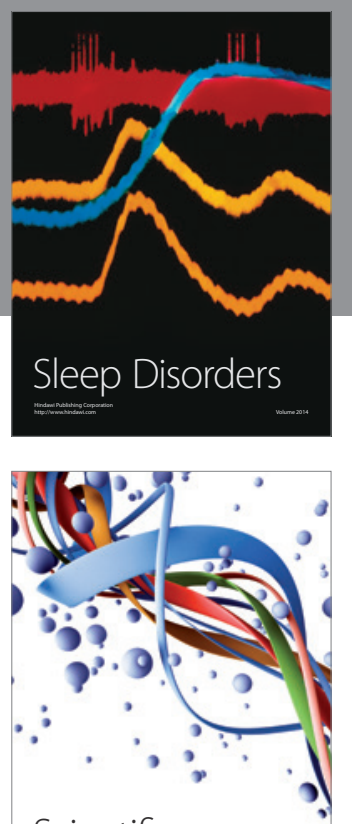

Scientifica
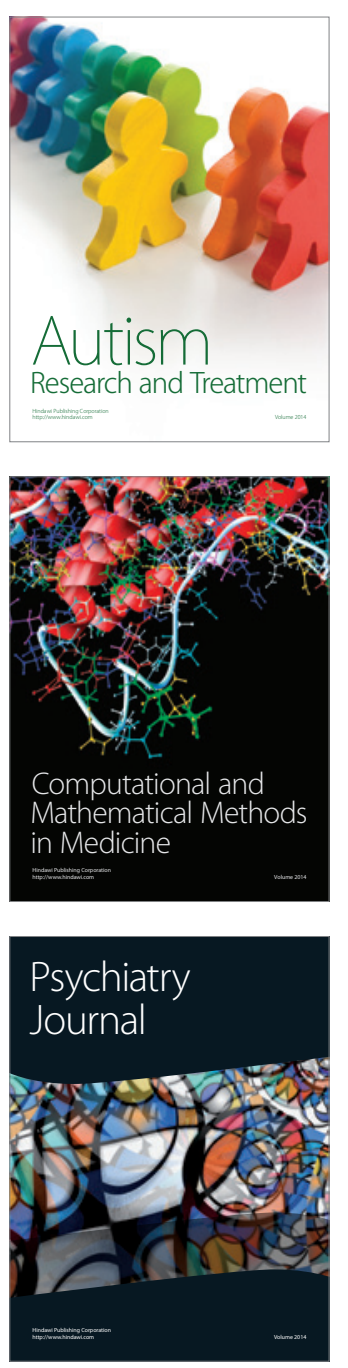
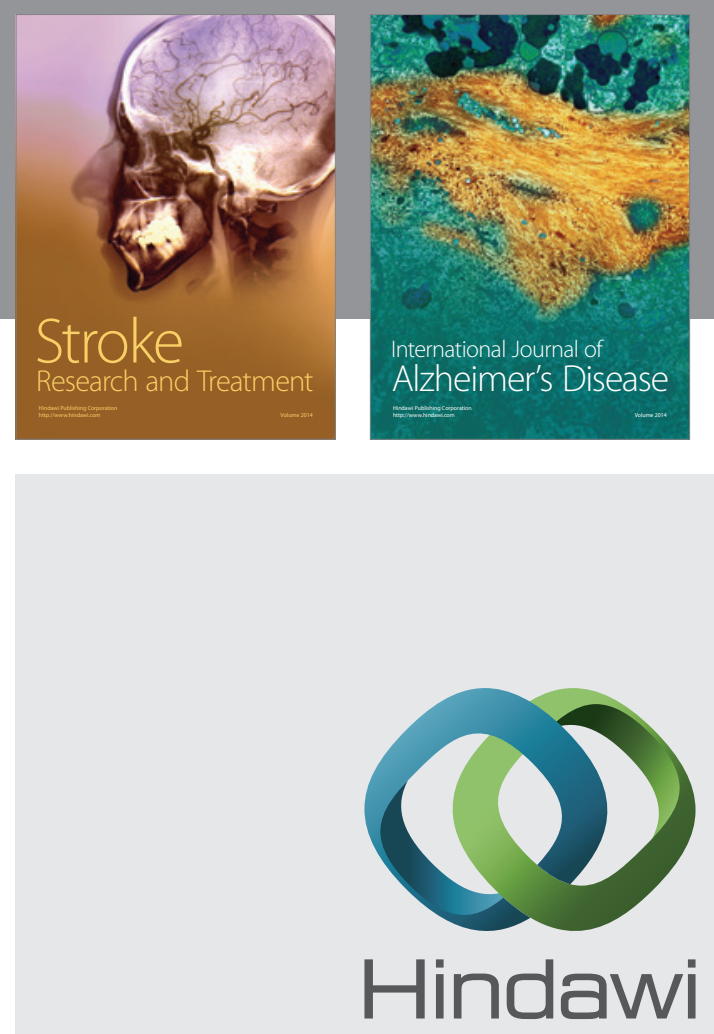

Submit your manuscripts at

http://www.hindawi.com
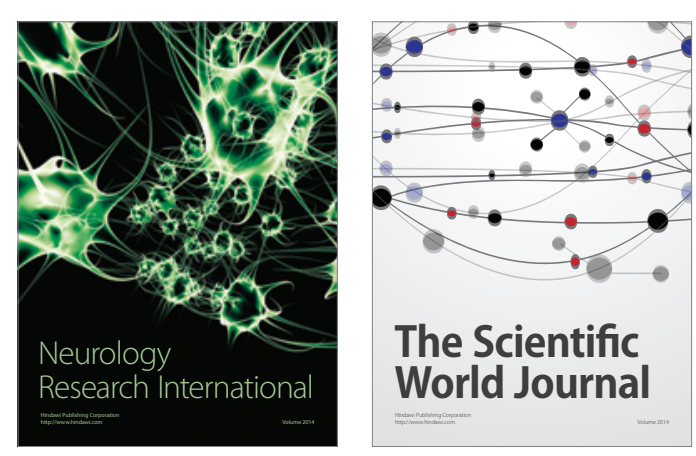

The Scientific World Journal

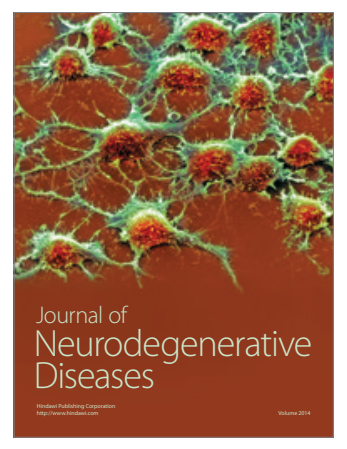

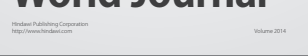

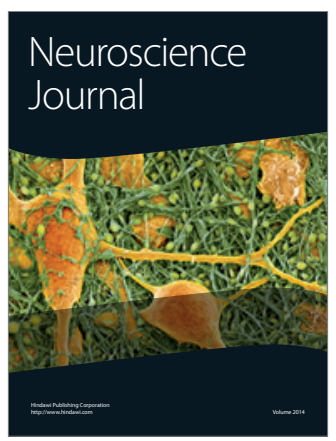

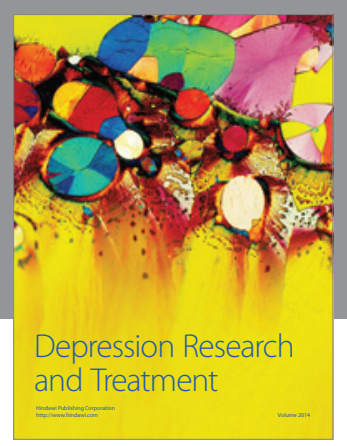
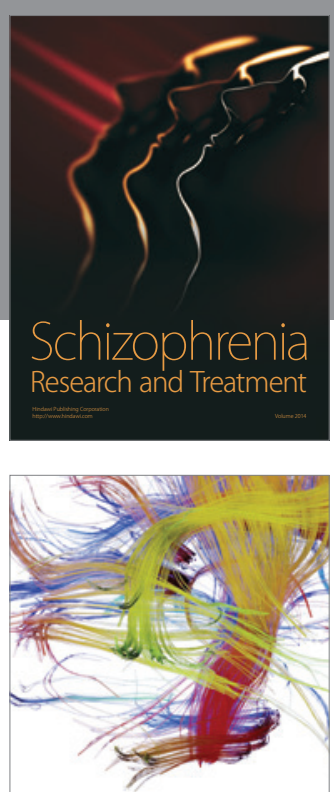

Brain Science

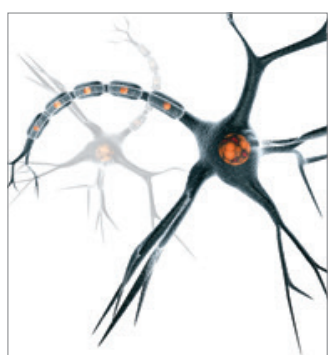

Neural Plasticity
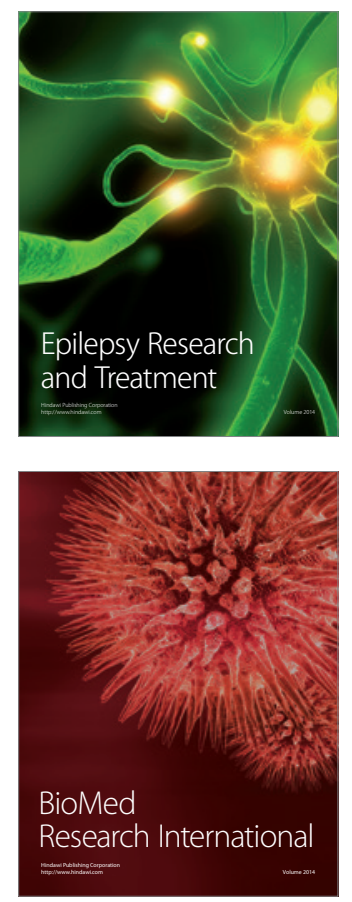

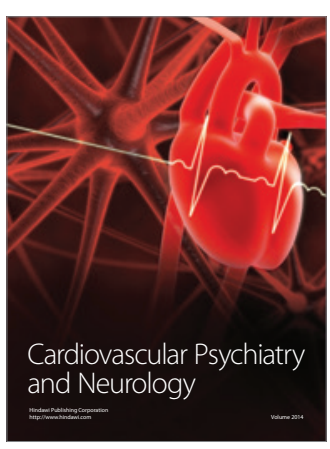

Parkinson's

Disease
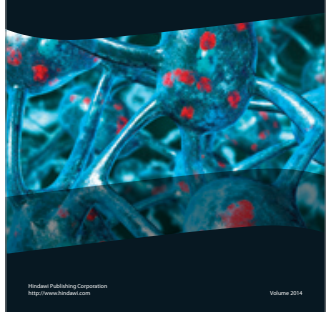